\section{( \\ EDITOR'S \\ CHOICE}

Department of Physical

Medicine and Rehabilitation, University of Michigan Medical

School, Ann Arbor, Michigan,

USA; Statewide Campus

System, Michigan State

University-College of

Osteopathic Medicine, East

Lansing, Michigan, USA

Correspondence to:

Dr E D Zemper, 325 E

Eisenhower, Suite 200, Ann

Arbor, MI 48108, USA;

zemp@med.umich.edu

Accepted 23 October 2009

Published Online First

4 November 2009

\title{
Catastrophic injuries among young athletes
}

\author{
E D Zemper
}

\section{ABSTRACT}

While very rare, catastrophic injuries in youth sports have a major impact on athletes and their families when they do occur. This article reviews and summarises the sparse research on direct catastrophic injuries in youth sports, a direct catastrophic sports injury being defined as a sport injury that resulted from participation in the skills of the sport, and resulted in a fatality or in a non-fatal brain or spinal cord injury, or skull or spinal fracture. While an electronic database search was completed to assemble the articles reviewed here, much of the data come from the National Center for Catastrophic Injury Research at the University of North Carolina, which has the most extensive and complete data set on this issue. This article reviews and summarises what is known about the rate of occurrence of these injuries in various youth sports, the risk factors for these injuries, injury mechanisms and what can be done to prevent them in various youth sports.

Due to their severe nature, catastrophic sports injuries usually receive considerable local media attention and, in the case of collegiate or professional sports, even national media attention. While these types of injuries are rare, they can cause permanent neurological deficits or even death, which can be devastating to athletes and their families. In addition, these types of injuries also can result in major long-term medical costs. This article will review the issue of direct catastrophic injuries among children involved in sports. The definition of direct catastrophic injury and related terms used here will follow that of Mueller and Cantu of the National Center for Catastrophic Injury Research at the University of North Carolina. ${ }^{12}$

- catastrophic injury: a sport injury that resulted in a fatality or in a non-fatal brain or spinal cord injury, or skull or spinal fracture;

- direct injury: those injuries that resulted directly from participation in the skills of the sport (this article will not consider indirect injuries, those caused by systemic failure as a result of exertion while participating in a sport activity or by a complication that was secondary to a non-fatal injury, for example, congenital heart conditions, heat-related injuries, complications arising during surgery or other treatment of a primary non-fatal injury);

- fatality: death;

- non-fatal injury: permanent severe functional disability resulting from the injury (eg, partial or complete paralysis);

- serious injury: no permanent functional disability, but a severe brain or spinal cord injury (eg, a fractured vertebra with no permanent paralysis).

Since this review is focused on children, collegiate sports will not be covered, since collegiate athletes typically are 18 years of age or older and not considered children. The primary means of collecting literature to review for this article was through use of electronic searches of Medline, PubMed, Sport Discus and Google Scholar Advanced Search, using the search terms: [athletic injuries OR sports injuries] AND catastrophic AND [adolescent OR youth OR children]. Approximately 150 articles were scanned for relevance to the topic at hand, and 25 were selected for use.

Most of the data collection and research on direct catastrophic sports injuries in children involve school-sponsored sports at the middle school and high school level. Some studies include recreational sports activities and organised youth sports outside the school venue and children younger than middle school or high school age. However, most of these studies cover a limited time frame or a limited geographic area (eg, from one hospital), and it is difficult to compare data across many of these studies because of differing methodologies, definitions and types of rates reported. There are also a few articles covering head and spinal cord injuries in recreational sport activities that do not differentiate between children and older age groups. ${ }^{34}$. Most data reviewed here represent middle-school and high-school-aged children participating in school-sponsored sports The most useful, comprehensive and consistent data on catastrophic injuries in youth sports are found in the website of the National Center for Catastrophic Injury Research at the University of North Carolina, directed by Dr Fred Mueller and Dr Robert Cantu (http://www.unc.edu/depts/ nccsi/), and in articles based on the centre's database. Therefore, this review will focus primarily on data from this source.

\section{EXTENT OF THE PROBLEM}

While direct catastrophic injuries are relatively rare in youth sports activities, they do occur, and some sports appear to carry a greater risk than others. In their review of head and neck injuries in young athletes, Proctor and Cantu list 21 sports or recreational activities with the highest head and neck injury rates. ${ }^{5}$ At least five of these are not normally practised by children (auto racing, motorcycle racing, hang gliding, parachute and sky diving). Of the remaining 16 , eight are not generally considered school sports in the USA (boxing, cycling, equestrian, martial arts, rugby, skating/rollerblading, skiing and trampolining). The remaining eight on this top 21 list are sports commonly sponsored by schools, for which we have more reliable data: diving (as an element of the sport of swimming), American gridiron football, gymnastics, ice hockey, lacrosse, soccer (football), 
track and field (athletics) and wrestling. Much of their data for non-school sports and activities were derived from the National Electronic Injury Surveillance System of the Consumer Products Safety Commission, which collects emergency department data from a statistical sample of 100 hospitals across the USA. From these data, estimates of numbers of injuries (not just catastrophic injuries) for the whole country are projected. However, it cannot be guaranteed that all injuries (or even catastrophic injuries) in a given hospital's catchment area pass through the hospital's emergency room, and the system estimates only numbers of injuries, since they have no means of estimating exposure/denominator data for calculating rates. Therefore, there is little real information available for these nonschool sponsored sports and recreational activities regarding rates of catastrophic injuries.

In another example from the UK, Silver reports on a series of 150 spinal injuries during a 34-year period, 121 of them cervical injuries, in the sports of rugby, trampolining, gymnastics and equestrian, but there are no exposure data available, so rates cannot be calculated. ${ }^{6}$ Another report, on paediatric injuries in US schools, was based on 7 years' data from the National Pediatric Trauma Registry, which collected data from 74 participating institutions from 30 states. There were 26 sports-related spinal cord injuries reported, 21 of them due to football and wrestling. But again, there were no exposure data, so rates could not be determined.

In Canada, Tator et al reviewed major head and neck injuries in ice hockey over a 26-year period beginning in 1966 and reported 241 cases, with a majority in players under 20 years of age. $^{8}$ They noted that the number of injuries per year had been increasing considerably since the early 1980s. Here again, no estimates of participation figures were available, and thus no rate estimates determined.

There are infrequent reports of rates of catastrophic injuries for non-school sponsored sports, such as a 10-year review of catastrophic cervical spine injuries in French rugby players. ${ }^{9}$ This report covered all ages, but sufficient information was presented to allow calculation of a rate of 0.36 catastrophic cervical spine injuries per 100000 participants over the 10-year period for players under 17 years old, and 5.5 per 100000 participants for players 17 to 21 years old.

Katoh et al maintained a national registry of spinal cord injuries in Japan during 1990 to 1992, and reviewed those specifically resulting from sports activity. ${ }^{10}$ They reported a mean of 1.95 severe sports-related spinal cord injuries per million population each year. These injuries occurred primarily in the sports of diving, skiing, football (rugby, American football and soccer), sky sports (parachuting and paragliding), judo and related martial arts, and gymnastics. In diving, football, gymnastics and judo, the greatest numbers occurred among participants between the ages of 10 and 20 years. Except for sky sports, the majority of injuries in each sport were cervical spine injuries.

While the great majority of catastrophic injuries in youth sports involve the head and spine, there is one other type of catastrophic injury that should be mentioned. Commotio cordis is an often fatal injury caused by blunt, non-penetrating trauma to the chest causing electrical disruption of cardiac rhythm (eg, ventricular fibrillation). Maron et al reviewed reports collected by a national commotio cordis registry. ${ }^{11}$ They found that of 128 confirmed cases, 78\% occurred in children less than 18 years old, with only a 16\% survival rate. Although these events can occur in non-sporting activities, $84 \%$ occurred in sports activities (62\% in organised sports), and $81 \%$ of the sports-related incidents were from a blunt precordial blow from a projectile (eg, baseball, softball, hockey puck, lacrosse ball). A majority of the sports-related incidents (58\%) occurred in baseball.

\section{National Center for Catastrophic Injury Research}

As noted previously, the most complete information on catastrophic sports injuries in youth is found in the database maintained at the National Center for Catastrophic Injury Research (NCCIR) at the University of North Carolina. Drawing on reports from coaches, athletic directors, athletic trainers, national athletic organisations, a national newspaper clipping service and a network of professional colleagues, centre staff communicate directly with coaches, administrators or physicians involved with each reported injury to collect detailed information on the circumstances, diagnosis and extent of each reported injury. Denominator data used for calculating rates are based on national participation data from the National Federation of State High School Associations (http://www. nfhs.org/). Table 1 summarises national participation data from 18 high school sports for the 26-year period (1982-1983 to 20072008) covered by the NCCIR. ${ }^{12}$ Table 2 presents the numbers of direct catastrophic injuries recorded by the NCCIR over the past 26 years for these 18 high school sports. ${ }^{13}$ From table 2, it is evident that American football has by far the greatest number of direct catastrophic injuries of any of the sports, averaging just over 24 per year, followed by cheerleading, averaging nearly three per year, then track and field, wrestling and baseball in that order.

Using the participation data in table 1 as the denominator or exposure data, and the numbers of injuries in table 2 as the numerator data, we can calculate direct catastrophic injury rates per 100000 participants per year for each sport (table 3). As can be seen, looking at rates rather than raw numbers of injuries changes the picture considerably. American football, which recorded over eight times as many injuries as the next leading sport (cheerleading), also has by far the most participants of any of the sports, so its rate of injury is only tied with gymnastics for the second highest rate. Ice hockey, with a mid-range number of injuries but one of the smallest participation rates, becomes the sport with the highest catastrophic injury rate. The school sports with the highest catastrophic injury rates, and therefore the highest risk level for these types of injuries, are ice hockey (2.39 per 100000 participants per year), football (1.78), gymnastics (1.78), wrestling (0.92), cheerleading (0.83) and lacrosse (0.83). The remaining sports have catastrophic injury rates of less than one-half per 100000 participants per year (or less than one injury per 100000 participants every 2 years), ranging down to 0.00 , or no catastrophic injuries in the last 26 years for water polo, tennis and golf.

Table 3 also shows that for all three categories of direct catastrophic injuries (fatalities, non-fatal and serious), males have considerably higher rates than females. Part of this may be explained by the fact that boys are taking part in more contact/ collision sports than girls, but even in sports they have in common, like gymnastics or track and field, the boys' rates often are much higher. Noticeable exceptions to this generalisation are ice hockey, where girls have a slightly higher rate (totally due to serious injuries), and cheerleading, where girls also have a higher rate.

The presence of ice hockey, lacrosse and American football among sports with the highest direct catastrophic injury rates is not surprising, given that they are contact sports, and football particularly being more of a high-velocity collision sport. Given 
Table 1 US high school sports participation for the period 1982-1983 to 2007-2008*

\begin{tabular}{|c|c|c|c|c|}
\hline Season & Sport & Male & Female & Totals \\
\hline \multirow[t]{5}{*}{ Fall } & American football & 35623701 & 17872 & 35641573 \\
\hline & Field hockey & 2781 & 1431676 & 1434457 \\
\hline & Cross-country & 4546218 & 3486467 & 8032685 \\
\hline & Soccer & 7175341 & 5184875 & 12360216 \\
\hline & Water polo† & 220778 & 180126 & 400904 \\
\hline \multirow[t]{6}{*}{ Winter } & Basketball & 13796973 & 11041039 & 24838012 \\
\hline & Wrestling & 6235016 & 46361 & 6281377 \\
\hline & Gymnastics & 98169 & 637467 & 735636 \\
\hline & Ice hockey & 722874 & 72537 & 795411 \\
\hline & Swimming & 2242814 & 2919225 & 5162039 \\
\hline & Volleyball: & 536747 & 5364475 & 5901222 \\
\hline \multirow[t]{6}{*}{ Spring } & Baseball & 10916754 & 23517 & 10940271 \\
\hline & Lacrosse & 858712 & 586973 & 1445685 \\
\hline & Track and field & 13266497 & 10747774 & 24014271 \\
\hline & Softball & 29743 & 8141827 & 8171570 \\
\hline & Tennis & 3677132 & 3832588 & 7509720 \\
\hline & Golf§ & 480989 & 199721 & 680710 \\
\hline Multiseasonal & Cheerleading & 452113 & 8590150 & 9042263 \\
\hline Totals & & 100883352 & 62504670 & 163388022 \\
\hline
\end{tabular}

${ }^{*}$ Cumulative total participation based on NFSHSA data summarised by Mueller and Cantu at the National Center for Catastrophic Injury Research website. ${ }^{12}$

†Data for 1992-1993 to 2007-2008.

\$Data for 1993-1994 to 2007-2008.

§Data for 2005-2006 to 2007-2008.

- Includes sideline cheer and competitive cheer; participation figures used the first NFSHSA survey of both types done in 20072008 as a basis for estimating 26-year totals (assuming cheerleading participation has increased at the same rate as other sports). NFSHSA figures did not give numbers for male and female participation; male participation based on $5 \%$ of total.

the nature of wrestling, with throws to a mat being a normal part of the activities of this sport, it is not surprising that it is high on this list as well. Gymnastics is not generally considered a contact sport, but in some respects it could be, given the risk of falls from various types of apparatus used in the sport. Cheerleading is probably the most surprising sport to see so high on the list, but in recent years it has changed from a simple leading of cheers on the sidelines to also include a competitive aspect much closer to gymnastics in nature. In many respects, competitive cheerleading could be considered a contact sport, involving activities that require a high degree of skill but, with the exception of shoes and possibly floor mats, utilising no personal protective equipment as required in most team contact sports, a characteristic it shares with wrestling and gymnastics.

The overall average across all 18 high school sports is 0.60 direct catastrophic injuries per 100000 participants per year (Table 3). Since there have been an average of almost 6.3 million participants per year in these high school sports during this period, that is an average of 37.7 direct catastrophic injuries per year. Since it cannot be guaranteed that all direct catastrophic sports injuries get reported to the NCCIR, these numbers and rates should be considered minimums. Still, these should be viewed in the context of approximately 3 million time-loss sports injuries per year in this age group, with approximately 770000 of them requiring physician visits, and approximately 45000 to 90000 requiring hospitalisation. ${ }^{14}$ In some respects, the ride in an automobile to and from a practice or game could be viewed as a more hazardous activity, as compared with the risk of a direct catastrophic injury during participation in the practice or game, since in recent years the rate for automobile accident fatalities (not including other categories of catastrophic injuries) for children aged 10-15 has been around 5.0 fatalities per 100000 per year..$^{15}$

\section{AETIOLOGY}

\section{Risk factors}

While studies investigating risk factors for general sports injuries are becoming more common, there still is a dearth of studies investigating risk factors for the rare catastrophic injuries. Data from the NCCIR indicate that a majority of athletes with catastrophic head injuries had a known previous mild head injury, most of them during that season. ${ }^{16}$ Schulz et al reported that after adjustment for sport, body mass index and year in school, history of concussion(s) remained a moderately strong risk factor for concussion among North Carolina high school athletes (rate ratio $=2.28 ; 95 \%$ CI 1.24 to 4.19 ). ${ }^{17}$

Instances dealing with catastrophic injury risk sometimes can be found in studies focused on general injury rates and patterns, such as the Schulz et al study of incidence and risk factors for injuries in cheerleaders. ${ }^{18}$ They demonstrated that the level of education and experience of the cheerleading head coach, and whether or not this individual had specific training on injury prevention, had a major impact on occurrence of injuries. They also noted that since the relatively recent inclusion of gymnastic elements in cheerleading, along with partner stunts and pyramids, these elements have been involved in a high proportion of cheerleader injuries. In ice hockey, risk factors that have been noted include aggressiveness and willingness to take risks, feelings of invincibility (probably related to all the protective equipment worn) and lack of awareness of the risk of spinal cord injuries, particularly in relation to checking from behind. ${ }^{8}$ Macnab et al found that failure to wear a protective helmet greatly increased the relative risk of head, neck and face injuries in skiers and snowboarders under 13 years old. ${ }^{19}$ Although studies like these are not necessarily focused on catastrophic injury risk, they do provide our best indirect indication of risk factors that should be considered relevant. 
늄

क्ल



焉
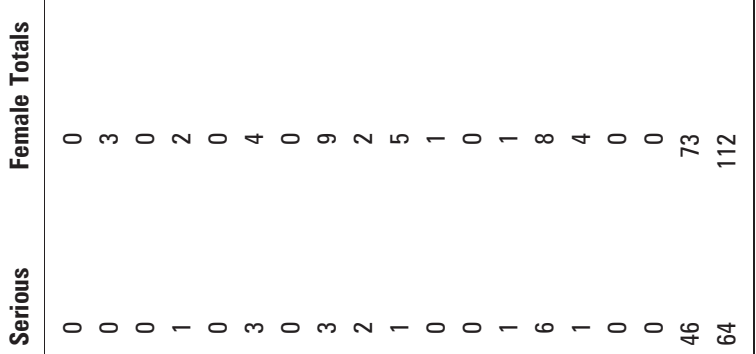

ฐ

产

$0 m 0-0-0,000-00-n 00 \frac{\pi}{4}$

窇

焉

$0000000000000-100 n+$

垔

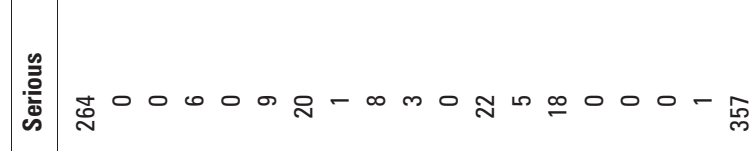

\section{璦}

产

D. 


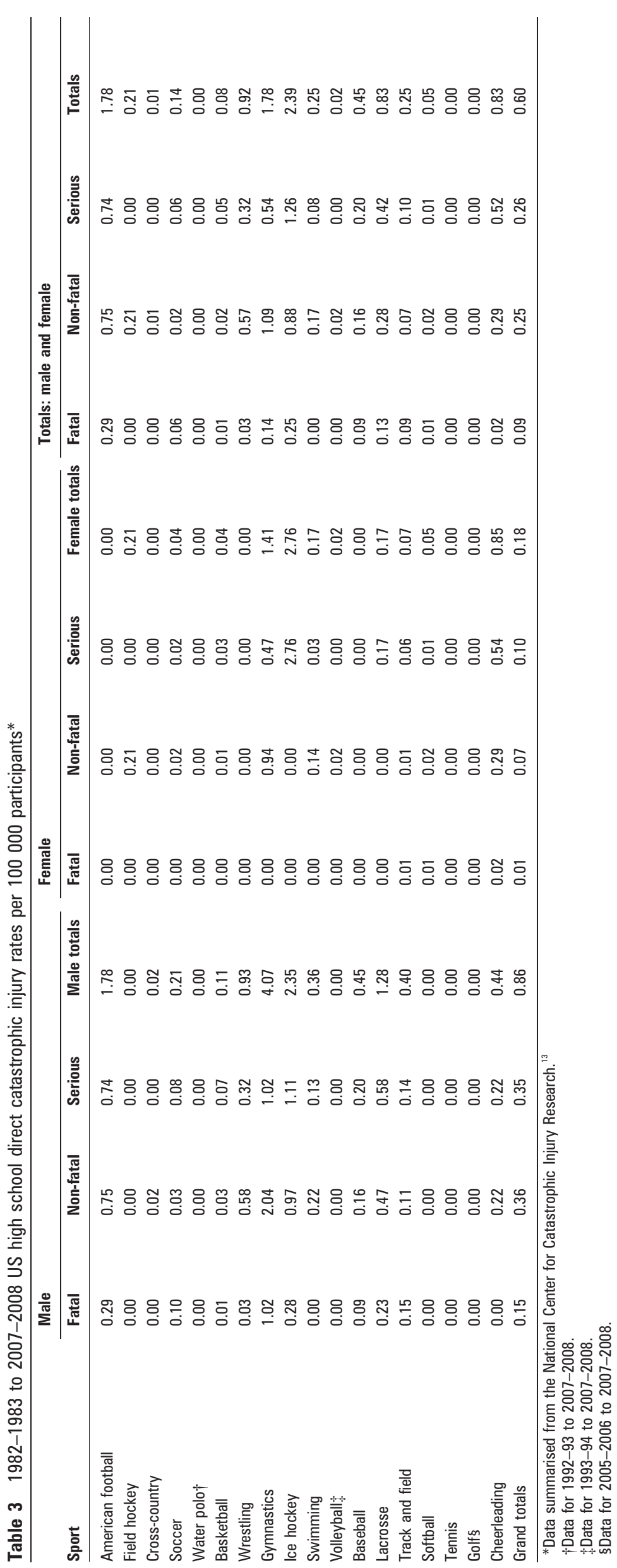




\section{Injury mechanism}

Given the nature of the major types of injuries being considered here, the aetiology of these injuries is not a subtle issue. They are caused primarily by direct forceful impact to the head or the spine. For head injuries it can be the result of an object (or person) hitting a non-moving head, or a moving head hitting a non-moving object (such as a wall or floor/ground), or two heads colliding, with resulting intracranial haemorrhage. For spinal injuries it could be a direct blow to the spine, or overextension or overflexion of the cervical spine. Another spinal injury mechanism involves compression injury to the cervical spine from a blow the top of the head while the neck is in a flexed position. ${ }^{5}$

As shown in table 2, the greatest numbers of these injuries occur in American football. Major head injuries in football occur most frequently while tackling, and most frequently as a result of helmet to helmet contact, but also as a result of helmet contact with another body part, such as an opponent's knee, or helmet to ground contact. ${ }^{16}$ Cervical spine injuries are most often associated with tackling and blocking, frequently as a result of the illegal practice of using the helmet as an initial contact point ("spearing"). ${ }^{20}$ The majority of direct catastrophic injuries in American football occur during games. ${ }^{50}$ Catastrophic injuries in lacrosse also are often the result of using the head as an initial contact point. ${ }^{13}$

In ice hockey the most frequent mechanism for direct catastrophic injuries, particularly cervical spine injuries, appears to be checking from behind with the checked player sliding forcefully head first into the boards. ${ }^{8}{ }^{13}$ In general, contact of the head with the boards, whether as a result of a check from behind or not, and contact with another player were the most frequent injury mechanisms. Contact with the ice or with the goal posts apparently is not a primary mechanism of neck injuries. $^{8}$

Gymnastics and wrestling share a common mechanism in contact of the head with the floor mat. Cheerleading also has a significant number of direct catastrophic injuries resulting from direct contact of the head with the floor (most often without protective mats) or ground, resulting from falls (or failure of other cheerleaders to properly catch) as the individual is dismounting from a pyramid or from a "basket toss," although other mechanisms occur, such as contact with another cheerleader's head or knee, or with a wall. ${ }^{21}$

Catastrophic injuries in competitive swimming are exclusively the result of racing dives into a too shallow pool during swim starts. ${ }^{13}$ This is similar to catastrophic injuries in recreational swimming, where neck injuries occur while diving into water that is too shallow. Soccer injuries, including fatalities, have occurred as a result of athletes being hit by a falling goal post that was inadequately anchored. While heading the ball has been a controversial issue in soccer, head injuries usually are the result of contact with another player's head or with the ground. ${ }^{13}$ While heading the ball does not appear to be an immediate cause of head injury, the cumulative long-term effects are still under investigation.

Direct injuries in baseball primarily have been associated with head-first sliding or with being struck with a thrown or batted ball. ${ }^{13}$ There are also injuries caused by collision between two players, and a few fatalities caused by commotio cordis, where a player is struck in the chest by a thrown or batted ball, causing cardiac arrhythmia. ${ }^{11} 22$

In track and field there are two primary causes of direct catastrophic injuries, both involving field events: head and neck injuries caused by missing or falling off the landing pad in the pole vault, or being struck by a thrown implement (shot, discus or javelin).$^{13}{ }^{23}$ In most of the pole vault injuries, the athlete bounced or fell off the landing pad onto a hard surface.

\section{PREVENTION}

As with risk factors, due to the rarity of these injuries there is a notable lack of studies testing the efficacy of measures to prevent catastrophic sports injuries at any level. There are examples where institution of equipment and rule changes at a specific time point can be seen after the fact to have had a positive impact. For instance, the institution of helmet standards and rule changes eliminating spearing and use of the helmet as an initial contact point in American football in the late 1970s appear to have significantly reduced the number of catastrophic injuries in that sport. ${ }^{20}$ In skiing and snowboarding there is evidence accumulating that the use of a helmet reduces the risk of major head and spinal cord injuries. ${ }^{3} 1924$

Some of the sports being considered here, such as American football with its high-impact nature, carry an inherent risk of major injury, and so a certain number of direct catastrophic injuries are going to be unavoidable, such as a player being flipped during a tackle and coming down head first onto the ground, or a player being inadvertently struck on the top of the helmet by another player's knee. Even sports that are not considered to be "collision sports" carry an inherent risk of major injury, however small, such as a baseball pitcher being at risk from a batted ball while still in the follow-through from a pitch. But a majority of these direct catastrophic injuries across all sports are believed to be preventable. General approaches to preventing catastrophic injuries that apply to all sports include ensuring adequate education of players, coaches and parents about the risks of catastrophic injuries and how they can be prevented; adequate enforcement by officials and coaches of rules designed to reduce the risk of these injuries; ensuring that protective equipment is adequate and properly fitted, used and maintained; and ensuring that practice and competition venues are adequately maintained and free of obstacles or hazards. ${ }^{25}$ In addition, it is important to have adequate medical coverage at practices and competitions in the event a major injury does occur. While a physician is not going to be available at all practices or competitions, a good "first line of defence" is the presence of a certified athletic trainer to provide immediate care and help reduce the risk of exacerbating major injuries and increasing the odds of a better outcome.

\section{American football}

With a great majority of direct catastrophic injuries occurring in American football, attention should be paid to prevention in this sport. A primary issue is the use of the head as an initial point of contact in tackling and blocking, which can cause both cervical spine injuries and brain injuries. This technique has been against the rules for many years now, and it is critical that all coaches teach proper blocking and tackling techniques that involve keeping the head up. ${ }^{20}{ }^{26}$ Players (and parents, who sometimes encourage "spearing" techniques) must be educated as to why proper "heads up" technique is important in preventing catastrophic injuries. And officials must be trained and encouraged to rigorously enforce the rules against initial contact with the helmet.

Another important issue with regard to prevention of catastrophic injuries is return to play after head injuries or concussions. ${ }^{27}$ Catastrophic injuries to the head can result from a single major blow to the head, or in some cases possibly from 
multiple blows to the head before the brain has fully recovered. ${ }^{5}{ }^{16}$ Data from the NCCIR indicate that 39 per cent of the athletes with catastrophic head injuries were playing with neurological symptoms at the time of the catastrophic event. ${ }^{16}$ Again, coaches, athletes and parents must be educated about concussion and its consequences, including what the signs of concussion are. A common problem is that many players never report symptoms of concussion, either because they do not know what they are or do not think they are that serious, or because they do not want to be removed from participation. One study found that less than half of players with concussion symptoms report their symptoms to a coach or athletic trainer. ${ }^{28}$ This becomes important because of the phenomenon of "diffuse cerebral swelling," a usually fatal condition resulting from diffuse swelling of brain tissue following brain trauma. Some clinicians have posited that this could be the result of a second blow to the head occurring before the symptoms from a previous head injury have cleared. ${ }^{5} 29$ However, based on their review of the existing cases, McCrory et a ${ }^{30-32}$ concluded that the published evidence for this premise is not compelling.

Because of the high mortality of the diffuse cerebral swelling syndrome, the decision about when to return a concussed athlete to participation becomes an important issue in preventing these occurrences. Concussive injuries often are rather nebulous in nature, and as a result historically there have been a number of approaches to classifying concussions and determining when to allow an athlete to return to participation following a concussion. In recent years a consensus has begun to develop, through a series of international conferences on concussion in sport, the most recent one occurring in Zurich in 2008. ${ }^{27}$ The most recent conference panel strongly endorsed the view that children should not be returned to practise or play until clinically completely symptom-free, which may require a longer time frame than for adults. ${ }^{27}$ And concern has grown beyond the sports community, to the extent that the state of Washington in the spring of 2009 passed a law requiring specific medical clearance before an athlete can return to participation after showing any signs of concussion. ${ }^{33}$ This recommendation that athletes not return to participation until all concussion symptoms have cleared applies to all sports, not just American football. Unfortunately, at the moment there is no clear consensus on return-to-play guidelines after cervical spine injury. ${ }^{34}$

\section{Baseball}

Prevention of catastrophic baseball injuries includes measures such as coaches emphasising proper skills to prevent fielding and base running collisions, using protective headgear and screens for pitchers during practice, eliminating or discouraging the head first slide and the availability of automatic external defibrillators in case of a commotio cordis injury. ${ }^{22}$ The use of softer-core baseballs has been proposed as a means of reducing ball-player impact injuries, but there appear to be no data showing that the softer ball has an effect in reducing injuries. ${ }^{22}$

\section{Competitive cheerleading}

Preventing catastrophic injuries in competitive cheerleading is somewhat more problematic, since it is a relatively new sport, and rules are still in the developmental stage. There have been recent rules limiting the height of pyramids and putting limits on the basket toss, two of the riskiest activities. As with other sports, there is a definite need for education and certification of coaches, and education of participants and parents about the risks of the sport and how injuries can be prevented. Not attempting tricks or routines for which everyone is adequately prepared and trained, including the spotters, is important. Mandating adequate floor mats for complex stunts is another important recommendation. ${ }^{21}{ }^{35}$ Another problem is that some cheerleading organisations still fail to see an injury problem for the sport and continue to make excuses for injuries, rather than joining the effort to adopt adequate safety measures. ${ }^{13}$ This is despite data showing that cheerleading has almost two-thirds of the direct catastrophic injuries reported for female high school athletes over the last 26 years (table 2 ), and has the fifth highest rate of direct catastrophic injuries (table 3).

\section{Gymnastics}

Until recent years, most catastrophic injuries in gymnastics involved the trampoline or mini-tramp. This equipment is no longer generally used in artistic gymnastics (although competition in the trampoline continues as its own sport). At this point, preventing catastrophic injuries in gymnastics involve the approaches noted previously with regard to education of coaches, participants and parents, and proper use and maintenance of equipment and facilities. ${ }^{36}$

\section{Ice hockey}

As with American football, prevention of catastrophic injuries in ice hockey involves education of coaches, players and parents. Everyone must be clear about proper and legal checking techniques, and there must be insistence that officials enforce the rules. ${ }^{8}$ The message from coaches and officials about the unacceptability of illegal checking must be clear and consistent.

\section{Soccer}

In soccer there has been some effort to introduce helmets to protect players while heading the ball, but this seems questionable since there is no evidence that heading the ball is a major cause of head injuries; most all head injuries are the result of head-to-head contact or contact of the head with the ground. One simple preventive measure is to ensure that soccer goals are adequately anchored so they will not tip over. They should be moved only by responsible adults, and players should not climb on the goal posts or hang from the crossbars. ${ }^{13}$

\section{Track and field}

To reduce the number of pole vault injuries in track and field, the focus should be on coaching proper techniques to "bail out" of a bad vault, and ensuring adequate (and properly placed) pads in and around the landing pit. The rules specifying the dimensions of the landing pads have undergone almost continuous modification in recent years, to the extent that the pole vault landing pit now is a very extensive, intricate (and expensive) piece of equipment. Helmets also have been proposed as a means of reducing head injuries in pole vaulting, and the rules now allow the use of helmets, but there are few models being manufactured specifically for pole vault, and there currently has been no standard developed for a pole vault helmet, as there has been for other sport helmets. Ensuring there are no hard surfaces around the landing pit (using pads on the ground surrounding the pit) also is critical. Rigorous enforcement of the high school rules about matching pole strength to athlete weight is necessary as well. ${ }^{23}$

Beyond the required use of a cage for the discus throw, prevention of direct catastrophic injuries in the throwing events 


\section{What is already known on this topic}

- Catastrophic injuries (fatalities or major injuries to the head or spine) are rare in youth sports.

- When they occur, they are devastating to the athlete and families involved.

- While participation in any sport involves an inherent risk of catastrophic injury, and many may be unavoidable, many more of them are felt to be preventable.

- Research on catastrophic injuries in youth sports is sparse, but useful data are starting to be accumulated through the efforts of individual researchers and organisations such as the National Center for Catastrophic Injury Research.

\section{What this paper adds}

- This review of the literature on catastrophic injuries in youth sports summarises what currently is known about the occurrence of these injuries in various youth and high school sports, and summarises suggested means of preventing them.

- This review highlights the relative scarcity of information on this issue, and the need for more extensive research on occurrence, risk factors and prevention.

is primarily a matter of inculcating certain safe habits in all those in the area of the events. Athletes, coaches and officials should never turn their back on the throwing circle or runway when in the landing area. Warm-ups and throws should never be done without direct supervision by officials or coaches. Landing sectors should be roped off, at least $3 \mathrm{~m}$ out from the landing sector lines, to keep spectators and athletes from wandering across the landing sector. During competition, and preferably during practices as well, athletes should never be allowed to walk into the landing sector to retrieve their implements; this should be done by an official or someone assigned to that duty. The throwing events in track and field are one of the few areas in sports where direct catastrophic injuries potentially are completely preventable, if the correct measures are put in place and rigorously practised.

\section{FURTHER RESEARCH}

More extensive injury surveillance systems are needed for coverage of direct catastrophic sports injuries. The National Center for Catastrophic Injury Research at the University of North Carolina has been doing admirable work for many years now covering high school and collegiate sports, and the information produced there is invaluable. But there are many sports and recreational activities that the NCCIR does not cover, and some sports like gymnastics are school sports, but the majority of participants are involved in non-school club programmes. This should be the responsibility of the national organisations overseeing or promoting these activities. Indeed, it is an ethical responsibility of these organisations. If they do not maintain the surveillance systems themselves, they should be providing financial and logistical support for those doing the work. Solid data on numbers, rates, aetiologies and circumstances of these injuries are needed before effective preventive measures to reduce the occurrence and severity of these injuries can be developed and tested. Because these injuries are relatively rare, large-scale ongoing surveillance systems will be necessary.

Competing interests: None.

Provenance and peer review: Commissioned; externally peer reviewed.

\section{REFERENCES}

1. NCCSIR: Definition of injury. http://www.unc.edu/depts/nccsi/NCCSIR injuryterms. html (accessed 1 July 2009)

2. Mueller Fo. Introduction. In: Mueller FO, Cantu RC, VanCamp SO, eds. Catastrophic injuries in high school and college sports. Champaign: Human Kinetics Sport Science Monograph Series, 1996:1-4

3. Ackery A, Hagel BE, Provvidenza C, et al. An international review of head and spinal cord injuries in alpine skiing and snowboarding. Inj Prevent 2007;13:368-75.

4. Reid DC, Saboe L. Spine fractures in winter sports. Sports Med 1989;7:393-9.

5. Proctor MR, Cantu RC. Head and neck injuries in young athletes. Clin Sports Med 2000;19:693-715.

6. Silver JR. Spinal injuries in sports in the UK. Br J Sports Med 1993;27:115-20.

7. DiScala C, Gallagher SS, Schneps SE. Causes and outcomes of pediatric injuries occurring at school. J School Health 1997;67:384.

8. Tator CH, Carson JD, Edmonds VE. Spinal injuries in ice hockey. Clin Sports Med 1998;17:183-94.

9. Bohu Y, Julia M, Bagate $C$, et al. Declining incidence of catastrophic cervical spine injuries in French rugby. Am J Sports Med 2009:37:319-23.

10. Katoh S, Shingu H, Ikata T, et al. Sports-related spinal cord injury in Japan (from the nationwide spinal cord injury registry between 1990 and 1992). Spinal Cord 1996:34:416-21.

11. Maron BJ, Gohman TE, Kyle SB, et al. Clinical profile and spectrum of commotio cordis. JAMA 2002;287:1142-6.

12. NCCSIR: Participation figures. http://www.unc.edu/depts/nccsi/AllSportTables.pdf (accessed 1 July 2009).

13. Mueller F0, Cantu RC. Catastrophic sports injury research: Twenty-sixth annua report. http://www.unc.edu/depts/nccsi/AllSport.pdf (accessed July 2009)

14. Conference on sports injuries in youth. Bethesda, Maryland: National Institutes of Health; 1992. NIH Publication No 93-3444 cited in: Hergenroeder AC. Prevention of sports injuries. Pediatrics 1998;101:1057-63.

15. http://www.disastercenter.com/traffic/AgeGroup.html (accessed July 2009)

16. Boden BP, Tacchetti RL, Cantu RC, et al. Catastrophic head injuries in high school and college football players. Am J Sports Med 2007;35:1075-81.

17. Schulz MR, Marshall SW, Mueller FO, et al. Incidence and risk factors for concussion in high school athletes, North Carolina, 1996-1999. Am J Epidemiol 2004;160:937-44.

18. Schulz MR, Marshall SW, Yang J, et al. A prospective cohort study of injury incidence and risk factors in North Carolina high school competitive cheerleaders. Am J Sports Med 2004;32:396-405.

19. Macnab AJ, Smith T, Gagnon FA, et al. Effect of helmet wear on the incidence of head/face and cervical spine injuries in young skiers and snowboarders. Inj Prev 2002;8:324-7.

20. Mueller F0, Cantu RC. Annual survey of catastrophic football injuries: 1977-2008 http://www.unc.edu/depts/nccsi/FootballCatastrophic.pdf (accessed 1 July 2009)

21. Boden BP, Tacchetti RL, Mueller FO. Catastrophic cheerleading injuries. Am J Sports Med 2003:31:881-8.

22. Boden BP, Tacchetti RL, Mueller FO. Catastrophic injuries in high school and college baseball players. Am J Sports Med 2004;32:1189-96.

23. Boden BP, Pasquina $\mathrm{P}$, Johnson $\mathrm{J}$, et al. Catastrophic injuries in pole vaulters. Am J Sports Med 2001;29:50-4.

24. Mueller BA, Cummings $P$, Rivara FP, et al. Injuries of the head, face and neck in relation to ski helmet use. Epidemiol 2008;19:270-6.

25. Hergenroeder AC. Prevention of sports injuries. Pediatrics 1998;101:1057-63.

26. Mueller F0, Colgate B. Annual survey of football injury research: 1931-2008. http:// www.unc.edu/depts/nccsi/FootballAnnual.pdf (accessed 1 July 2009)

27. McCrory P, Meeuwisse W, Johnston K, et al. Consensus statement on concussion in sport-The 3rd international conference of concussion in sport held in Zurich, November 2008. Br J Sports Med 2005;43:i76-84.

28. McCrae M, Hammeke T, Olsen G, et al. Unreported concussions in high school football players: implications for prevention. Clin J Sport Med 2005;14:13-17.

29. Anonymous. Sports-related recurrent brain injuries-United States. MMWR 1997:46:224-7.

30. McCory PR, Berkovic SF. Second impact syndrome. Neurology 1998;50:677-83.

31. McCrory P. Does second impact syndrome exist? Clin J Sport Med 2001;11:144-9

32. Johnston KM, McCrory P, Mohtadi NG, et al. Evidence-based review of sportrelated concussion: Clinical science. Clin J Sport Med 2001;11:150-9.

33. American College of Sports Medicine: Youth concussion issue takes center stage. ACSM Sports Medicine Bulletin 2009. http://www.multiview.com/briefs/acsm/ ACSM100609.php\#5 (accessed 1 October 2009).

34. Morganti C, Sweeney CA, Albanese SA, et al. Return to play after cervical spine injury. Spine 2001;26:1131-6.

35. Shields BJ, Smith GA. Cheerleading-related injuries to children 5 to 18 years of age: United States, 1990-2002. Pediatrics 2006;117:122-9.

36. Caine DJ, Lindner KJ, Mandelbaum BR, et al. Gymnastics. In: Caine DJ, Caine CG, Lindner KJ, eds. Epidemiology of sports injuries. Champaign: Human Kinetics, 1996:213-46. 